\title{
OUTCOMES OF AN EXPERT SURVEY: ARE SINGAPORE'S MANUFACTURING SMALL AND MEDIUM ENTERPRISES READY TO EMBRACE INDUSTRY 4.0?
}

\author{
Gopalakrishnan Surianarayanan ${ }^{1}$ and Thomas Menkhoff ${ }^{2}$ \\ ${ }^{1}$ DBA Student \\ ${ }^{2}$ Professor of Organisational Behavior and Human Resources \\ Singapore Management University, Lee Kong Chian School of Business, 50 Stamford Rd. \#05-01, Singapore 178899
}

\begin{abstract}
Industry 4.0 encompasses adopting opportunities from end-to-end digitalisation with connected computers and increasingly autonomous automation systems equipped with intelligent machine learning algorithms that control the robotics without much input from humans. Smart manufacturing technologies (a part of the smart industry, an extension of Industry 4.0 initiatives and implementation) involve automating various processes. It aims to connect various units in real-time while enhancing profitability by reducing costs, increasing labour productivity, and improving overall efficiency.

The impetus for our paper is the assumption that the adoption of smart manufacturing technologies such as advanced robotics, cyber-physical systems, or the Internet of Things (IoT) continues to be a challenge for Small and Medium Enterprise (SME) manufacturing firms in Singapore. Industry 4.0 adoption issues include significant capital investment, developing technical skills, recruiting new talent, re-skilling of the workforce, training needs, top management support, etc. But the traditional manufacturing model is fast evolving. Ultimately, adopting the right enabling technologies in a phased manner with proper planning remains a critical factor for the success of Industry 4.0 initiatives.

This paper contributes to the minimal Asian management literature about Industry 4.0 matters in SMEs by interviewing eight key experts who are very knowledgeable about the subject matter. The qualitative study sheds light on the drivers and barriers to better understand current business dynamics, potential issues, focus areas, and initiatives to smoothen this implementation, to help catapult local manufacturers to the next level. A structured questionnaire was designed based on the current body of knowledge to conduct qualitative semi-structured interviews with key specialists and decision-makers across Government agencies, Institutes of Higher Learnings (IHL's), suppliers/providers of Industry 4.0 technology, business associations, and the SME sector.

The analysis of the interviews suggests that factors or drivers such as technology push by the Government with robust funding and training support, skilled labour shortages including imported labour dependence, productivity and efficiency issues, the pressure to innovate business models due to increased competition, and the impact of Covid-19 are propelling SMEs to adopt Industry 4.0. Some of the barriers include high investment costs and return on investment concerns, capability concerns, mindset issues, and lack of ecosystem concerns. The extent to which local SMEs are ready for Industry 4.0 will be further examined during the $2^{\text {nd }}$ phase of the research project.
\end{abstract}

\section{KEYWORDS}

Industry 4.0, Smart Manufacturing, SME’s, Qualitative, Business Model Innovation, Barriers to Adoption

\section{INTRODUCTION}

The First Industrial revolution commenced at the end of the 18th century and involved the mechanization through water and steam power. The Second Industrial Revolution, which originated at the start of the 20th century, involved mass production using assembly lines with electricity and division of labour. Great Britain and the United States of America were the leading proponents of the 1st and 2nd Industrial Revolution. The Third Industrial revolution commenced in the 1970s and is signified by computers and automation - it is widely prevalent even today and inter-connects associated fields like information technology, electronics, and operations technology seamlessly. 
The term "Industrie 4.0," also known as I4.0 or I4, originated in Germany and was coined in the Hannover Fair during 2011. Other leading industrial nations have widely recognised it - the United States calls it the "Connected Enterprise," and the United Kingdom refers to it as the "Fourth Industrial Revolution."

Industry 4.0 adoption is expected to profoundly impact the entire spectrum of industries, especially in manufacturing. By using a confluence of automation, data, and digitalisation, Industry 4.0 aims to radically transform how organisations operate presently while increasing productivity, enhancing flexibility, reducing costs, and improving efficiency. More companies are strategically embracing so-called Industry 4.0 approaches to leverage opportunities arising from newly connected computers and increasingly autonomous automation systems (e.g., robotics), equipped with intelligent machine learning algorithms that control the robotics without much human input. In these 'smart' factories, cyber-physical systems (i.e., independently operating systems that self-optimize and communicate with each other, and ultimately optimize production) monitor the physical manufacturing processes and play an increasingly important role in terms of decision-making.

Industry 4.0 signifies three mutually interconnected factors (Zezulka et al., 2016), namely digitisation and integration of any technical-economic networks, digitisation of products and services, and new market models. At the core of this new smart manufacturing paradigm (McKeven, 2015) is the Internet of Things that drives the conversion of traditional factories into a 'smart' manufacturing environment called "Industry 4.0" (Kagermann et al., 2013), resulting in an increasingly intelligent, connected, and autonomous factory with outstanding dynamic capabilities (Teece, 2010; Eisenhardt and Martin, 2000). Smart manufacturing technologies include big data processing, machine learning, advanced robotics, cloud computing, sensors technology, additive manufacturing, and augmented reality (McKeven, 2015). By using predictive big data analytics, deep learning, or sentiment/image analysis, business leaders can identify patterns and trends in vast reams of big data. It allows them to make 'smarter' decisions (e.g., about the loss of customers or the necessary service inspection of equipment) and potentially to become more competitive in real-time.

\section{RESEARCH VISION, RATIONALE AND QUESTIONS}

\subsection{Conceptual Framework: Industry 4.0}

Characteristic features of an Industry 4.0 system (Marr, 2016; Schwab, 2016) include interoperability (machines, devices, sensors, and people that connect and communicate with one another), information transparency (the systems create a virtual copy of the physical world through sensor data to contextualize information), technical assistance (both the ability of the systems to support humans in making decisions and solving problems and the ability to assist humans with tasks that are too difficult or unsafe for humans) and decentralized decision-making (the ability of cyber-physical systems to make simple decisions on their own and become as autonomous as possible).

"The term Industry 4.0 stands for the fourth industrial revolution and is best understood as a new level of organization and control over the entire value chain of the life cycle of products, and it is geared towards increasingly individualized customer requirements" (Koch et al, 2014).

"Industry 4.0 or Smart industry refers to the technological evolution from embedded systems to cyber-physical systems. It connects embedded system production technologies and smart production processes to pave the way to a new technological age which will radically transform industry and production value chains and business models" (MacDougall, 2014).

\subsection{Conceptual Framework: Sustaining Singapore's Competitiveness in Manufacturing and Technology Innovation through Industry 4.0}

Industry 4.0 initiatives are also finding increased interest across South East Asian economies (ASEAN) over the last few years, with most governments taking active measures to push towards this implementation. ASEAN aspires to be the world's 4th largest economic block by 2050, and Industry 4.0 is a critical element of 
this growth vision across the region. Most countries, including Singapore, have created a road map with a vision for Industry 4.0. However, there is arguably limited adoption despite all the initiatives and support extended by the various Governments.

The manufacturing sector is critical for Singapore's economy as it makes up about $21 \%$ of Singapore's GDP, accounting for $14 \%$ of its workforce. Due to the lack of research data on the firms' receptiveness towards advanced Industry 4.0 technologies, it is critical to examine the impact of automation, digitization, and web-based production systems on the business models of local manufacturers in terms of successful 'production optimization', greater 'product customization,' 'predictive' maintenance and 'visionary' investments into automation solutions. According to the Singapore Business Federation, about $60 \%$ of local small and medium-sized enterprises have not made significant technological changes. Possible reasons include resistance to change, lack of technological knowledge and resources, and insufficient leadership foresight. Many local firms are still operating in 'the Industrial 2.0/3.0' era rather than embracing opportunities arising from smart 'Industry 4.0' technologies. In smart factories, cyber-physical systems (i.e., independently operating systems that self-optimize and communicate with each other) monitor the physical manufacturing processes and play an increasingly important role in decision-making. At the core of this new smart manufacturing, the paradigm is IoT, resulting in an increasingly intelligent, connected, and autonomous factory with excellent dynamic capabilities.

We expect that there is great variance amongst local manufacturing firms concerning the adoption of smart factory technologies ranging from (i) those that are entirely ignorant about the advantages of Industry 4.0 to (ii) those that are learning to implement such systems and (iii) experienced technological leaders. Many local SME's are contract manufacturers and may sense that it is not advantageous to embrace new technologies before their Principals do so. Others might have successfully implemented very comprehensive Industry 4.0 activities in addition to launching their workforce transformation programmes, e.g., to impart automation skills into the workforce.

Singapore has an adequate level of understanding with companies of the need to migrate to Industry 4.0, and the benefits of implementing this also generate much excitement. However, unlike Germany or the United States, the pace of adoption has been muted beyond a few early adopters. The Economic Development Board (EDB) in Singapore launched a Smart Industry Readiness Index (Siri) in 2017 to help firms measure their progress and to understand the gaps in implementation. Technology, Process, and Organisation were the three building blocks of Industry 4.0 identified by EDB. The Model Factory at A*Star's Advanced Remanufacturing and Technology Centre and the Operation and Technology Roadmap (OTR) launch enables firms to realise their transformation on this smart manufacturing journey. However, the take-up rate by companies seems to be still low.

Locally, efforts are underway to leverage the smart manufacturing technology potential in Singapore's manufacturing industry, representing a core sector within Singapore's economy. In 2015, the Agency for Science, Technology, and Research (A*STAR) started a Future of Manufacturing (FoM) Initiative in close consultation with the Ministry of Trade and Industry (MTI), the Economic Development Board (EDB), and SPRING Singapore under the Government's Research, Innovation \& Enterprise 2020 plan. The deliberations involved extensive engagement with industry and trade associations. The initiative's goal is to sustain Singapore's competitiveness in manufacturing and technology innovation. It is a location of choice for developing, test-bedding, and deploying advanced breaking-ground technologies in the manufacturing sector. "The three key thrusts of $A * S T A R$ 's FoM Initiative are the public-private partnership platforms of Tech Access, Tech Depot, and Model Factories, that aim to drive technology innovation, knowledge transfer and adoption across the manufacturing industry (A*STAR Science and Engineering Research Council (SERC)."

\subsection{Conceptual Framework: Purpose of Research and Research Question}

There are limited Singapore studies to understand the driving forces and barriers in adopting and implementing Industry 4.0. Most studies focus on the technology aspects and provide limited understanding from SME's holistic business model viewpoint. According to the Singapore Business Federation, about $60 \%$ of local SME's have not made significant adjustments to adapt to technological change. The paper attempts to address this significant knowledge gap and contribute to the minimal Asian management literature about the smart manufacturing technology research gap's impact on understanding the experts across the ecosystem. We believe that this approach will help us better understand current business dynamics, potential 
issues, focus areas, and developments related to the pace of adopting advanced manufacturing approaches within Singapore's manufacturing sector to help catapult Singapore's manufacturers to the next level. The core research question addressed in the paper is the following: Are Singapore's manufacturing Small and Medium Enterprises ready to embrace Industry 4.0?

\section{RESEARCH DESIGN}

\subsection{Method}

Our study adopted a dual-phase approach to developing a model that can clarify factors influencing the readiness of SME's for the adoption of Industry 4.0. The first phase involves expert semi-structured interviews with eight key decision-makers and heads across Government agencies, Institutes of Higher Learnings (IHLs), suppliers/providers of technology, business associations and the local SME sector. A structured questionnaire was devised based on the current body of knowledge in Industry 4.0.

The objective of the expert interviews was to allow us to dive deeper into the issues involved so as to develop a comprehensive understanding of the challenges faced by SMEs in Singapore. It also allowed us to draw on the expert insights with candour. The qualitative approach allows the interviewees to express themselves freely while providing us with the option to seek additional inputs and quality guidance. "Qualitative research is conducted through intense and prolonged contact with a 'field' or life situation" (Miles and Huberman, 1984).

Based on a literature review, we structured a questionnaire for the expert interviews and eventually arrived at several factors or categories (see Table 1 below) impacting Industry 4.0 adoption in SMEs after the text materials had been analysed. We conducted the eight interviews over virtual meetings application (ZOOM) and recorded the interviews with the participants' permission. The interviews were transcribed verbatim using transcription software and subsequently analysed for emerging themes using software (Nvivo).

Table 1. Factors impacting Industry 4.0 adoption in SME's

\begin{tabular}{ll}
\hline$\#$ & Factors \\
\hline 1 & Capability and Competency \\
2 & Collaboration - Internal and External \\
3 & Culture of Company \\
4 & Business Model Innovation \\
5 & Skilled Labour Shortage and Dependencies \\
6 & Mindset and Resistance to Change \\
7 & Productivity and Efficiency \\
8 & Return on Investment and Capital Costs \\
9 & Government Subsidies, Incentives and Support \\
10 & Talent Shortage \\
11 & Technological Push by the Government \\
12 & Top Management Support \\
13 & Turnkey Solution Providers \\
14 & Uniform Standards \\
15 & Strategy and Implementation Roadmap \\
\hline
\end{tabular}

Qualitative data analysis techniques are well established in the management field, comprising three different procedures: data reduction (e.g., discarding irrelevant data in transcripts), data display (e.g., specific graphical formats derived from the data), and drawing conclusions based on field notes and emerging themes (Miles and Huberman, 2014). In line with the criteria of qualitative research, respondents' transcribed statements were clustered into common (raw data) themes and grouped into so-called first-order themes. Units with different meanings and general dimensions were established based on second-order themes (Eisenhardt and Graebner, 2007; Gioia et al., 2013). Table 1 summarizes the key outcomes of this step. 


\subsection{Data Collection and Analysis}

Table 2 presents the profiles of the interviewed experts:

Table 2. Profile of experts interviewed

\begin{tabular}{lll}
\hline$\#$ & Designation & Industry \\
\hline 1 & President & Industry Association \\
2 & President - APAC & Multi-National Company - Provider of Technology \\
3 & Executive Vice President - APAC & Multi-National Company - Provider of Technology \\
4 & Director and Head of Industry 4.0 Labs & Institute of Higher Learning (IHL) \\
5 & Professor and Head of Industry 4.0 Track & Institute of Higher Learning \\
6 & Director & Government Agency for Industry 4.0 \\
7 & Deputy Director and Head (SME) & Government Agency - Industry 4.0 Technology \\
& & Support and Upgrade \\
8 & Head and Project Manager & Early Adopter of Industry 4.0 (SME) and Model \\
& & company/example in Singapore \\
\hline
\end{tabular}

\section{FINDINGS}

The expert interviews helped to identify five key drivers and four main barriers with regard to the adoption and implementation of Industry 4.0 approaches as illustrated in Figure 1.

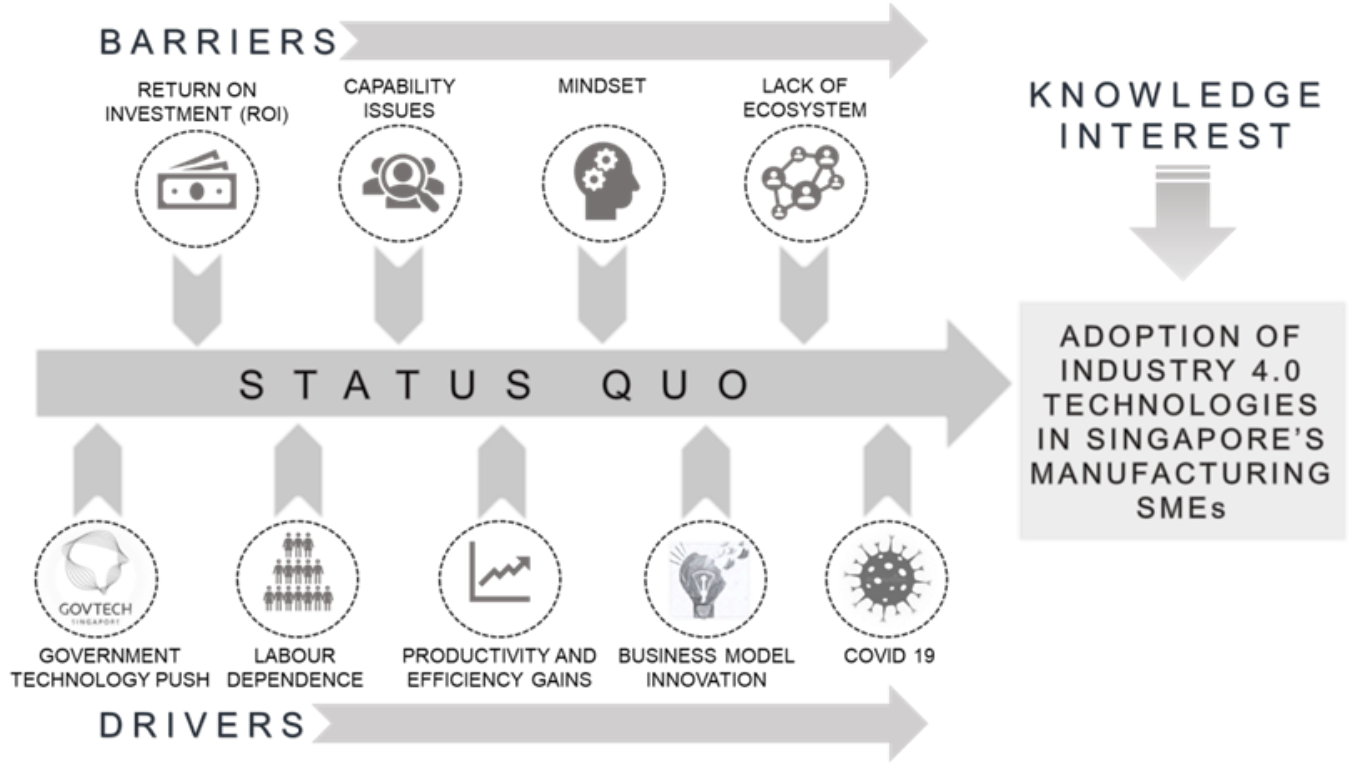

Figure 1. Drivers and barriers of Industry 4.0 adoption and implementation

Key drivers include technological push and incentives by the Government, skilled labour shortages, productivity and efficiency gains, the pressure to innovate business models due to increased competition, and the impact of Covid-19. Barriers in adoption revolve around return on investment issues, capability constraints, lack of ecosystem, and mindset factors. All experts agreed that Industry 4.0 was well recognised across the manufacturing SMEs in Singapore due to the top-down kind of initiatives embarked upon by the Government in Singapore and well supported by the agencies supporting this initiative.

"This is because Singapore has identified Industry 4.0 as an important skill and an important capability to improve productivity and to keep manufacturing content as a percentage of GDP existing in Singapore, and of course there has been a lot of downward pressure on that over the last few years."

(Interviewee 2) 
The expert views were varied in terms of readiness to adopt and implement Industry 4.0 and SMEs' capabilities. They ranged between 5 to 7 on a scale of 0 to $10(0=$ very low $-10=$ very high $)$ to measure SME's readiness and capabilities to adopt and implement Industry 4.0 initiatives. The size and sector in which the SME operated played a crucial role in adopting Industry 4.0. It was unanimously felt that larger SMEs (USD 100 million and above) were very well-positioned to embrace Industry 4.0. In contrast, medium-sized SMEs (USD 10 - 100 million) were now more willing to embrace, especially on the back of Covid-19 bottlenecks and issues. Smaller SMEs below USD 10 million did not recognise Industry 4.0 benefits and were not on board due to various constraints with investment and operation scale as a hindrance. We observed that specific sectors such as hi-tech manufacturing, electronics, semiconductors, medical equipment, etc. were very well positioned to benefit from Industry 4.0 initiatives and SMEs in these sectors. One of the main drivers has been the continuous operation of these manufacturing lines in factories $24 \times 7$, 365 days per year, resulting in a more straightforward justification on the capital costs employed and the size of end products that were more suitable for smart manufacturing facilities. On the other hand, traditional sectors like construction, oil, and gas, amongst others, were considered to be slow adopters. The Covid-19 pandemic was viewed by most experts as a watershed moment in the adoption of Industry 4.0, even by traditional companies.

"The writing is on the wall with COVID coming in. I think Industry 4.0 will get an impetus in terms of people wanting to adopt/upgrade or maybe at least have the interest because traditional construction companies would not have changed their model."

(Interviewee 5)

"During this time, we have seen a ten-fold increase within the last six months of enterprises embarking on that journey."

(Interviewee 1)

The primary consideration here was that barring some companies who had truly embraced Industry 4.0, most SMEs were still unable to adopt Industry 4.0 despite the sound support on the Government's technical front and financial aspects. The overarching concerns' uniformly arising from all experts was the high investment, capital cost outlays, and economies of scale concerns expressed by most SMEs.

"I am not saying the small size SME cannot implement Industry 4.0, but what I am saying is if you want to reap the benefit of Industry 4.0 and you do not have that size, the cost will become very high, your returns might scare a small micro SME away. How are they going to achieve their ROI since every SME exists for the bottom line?"

(Interviewee 8)

"Our focus in the last couple of years has been more with the MNC's actually because there has been a lot of more activity, we have dedicated innovation budgets actually, for them it is a part of global roll-outs, and it comes out much more naturally. We are spending much less time discussing why this is necessary and ROI and business cases, and so honestly, not that many good examples. Most of our Industry 4.0 deployment is still with the larger players."

(Interviewee 2)

One of the critical drivers of Industry 4.0 approaches was the overarching need by SMEs to embrace business model innovation due to various factors such as a need to improve their revenue streams and cost structures and to build a robust value proposition. These needs were further exacerbated by issues like low productivity, high labour cost, increased competition due to globalisation, the impact of Covid-19, etc.

"At this timing where your equipment is not doing anything anymore, your systems are idle, especially on weekends, but if you can continue operation on the weekends, that is actually a lot of large productivity gains and gain to an additional base as well."

(Interviewee 5) 
"Covid-19 presents us this opportunity to hammer down on SME's to adopt Industry 4.0 or smart manufacturing technologies in a bigger way now and also to maybe drive innovation also, where some SME's especially a large proportion in Singapore, have not kept up with as yet."

(Interviewee 2)

“We did not do this to cut the workforce. We did this project to increase productivity."

(Interviewee 8)

Good examples exist across SME's, which show very healthy ways to innovate their business models by undertaking Industry 4.0, including ways to convert from Capital Expenditure (CAPEx) to Operational Expenditure (OPEx) methods alongside services like predictive maintenance approaches. This approach allows companies to collect a premium for their end customer services over a longer time frame and a strong incentive to better service the asset. Digital technologies also facilitate collecting a considerable volume of data from production facilities, customer locations, entire supply chains, etc. which will significantly support decision-making and optimising processes.

"I think business model innovation is genuine, right. There is a huge driver where business model innovation plays a role - like this company I mentioned before, going away from pure re-selling of assets to a model where they are trying to add services on top, which is the first step. However, if you have the insight into what is happening inside the machine, there is nothing that prevents you from putting that asset on to your balance sheet. You can then run it as an operational asset and then collect a premium as you take the capital cost on your side and amortising it over a longer period while getting a premium to finance and run the asset. You also get a strong incentive to maintain the asset well, which before then, was not necessarily an incentive. You may have differently aligned incentives, and you have maybe more an incentive now to drive maintenance. So for the end customer, it is a good thing as you get the alignment of incentives, and they would be willing to take that risk and give some margin to the provider of the manufacturing equipment also."

(Interviewee 2)

A phase-wise approach to adopt Industry 4.0 was seen as the preferred way to get started according to some experts. This approach allowed the SME not to disturb their entire facility, absorb technology in stages, and amortise the capital investments over a broader horizon. The technical support and push to pursue Industry 4.0 and related automation was something that most interviewees felt was done very well by the Government. To further complement this push, the Government has been going all out to provide financial assistance, subsidies, and even offers in terms of technical consultancy to motivate SMEs to go on the path of Industry 4.0. Some interviewees felt that the high level of support from the Government had, on the contrary, made some of the SME's sit back and wait for incentives rather than drive forward and innovate to thrive and survive. SMEs' capability to engage in innovation and differentiate competitively in a global supply chain rather than local supply chain was also a limitation in some instances. Factors relating to human capital, including capability issues, skilled labour shortages, dependency on imported labour, and a dearth of top talent to meet companies' evolving needs, also formed a critical theme across all interactions.

"We are talking exactly about the capability of SMEs to innovate and transform. Moreover, human capital is missing in these SME's."

(Interviewee 2)

"What motivated us to go towards Industry 4.0 is because we faced a skilled labour shortage. We needed much-skilled labour, and we have been facing many challenges in getting skilled labour in the machining of our components."

(Interviewee 8)

A key consideration was the top management support, organisational resistance across ranks, and a culture shift focusing on managing its mindset. The vision and direction provided by the CEO and senior management was an extremely critical aspect. In the case of family-owned companies, it was felt that the younger generation's engagement to harvest the benefits of smart manufacturing was a huge determinant in their success. 
"Our CEO is the one; he is the main driver who wanted to adopt the technology. So he took the opportunity to convince the board to go towards Industry 4.0 technology and grow the revenue - the top line and bottom line. Thus, the board was convinced, and therefore they gave him that support. Moreover, with that support - that is the first stage. It is the commitment and belief of the person who wants to implement it. He had to be on the top to be the main decision-maker."

(Interviewee 8)

One of the surprise benefits achieved due to Industry 4.0 adoption highlighted by an interviewee, was that the new hires were attracted to pursue their careers in these companies, which helped attract the best talent in the market among the new graduates.

"We did find that there is much resistance. It is not easy, so we have to do it systematically. Luckily we devised our in-house training roadmap. We do some in-house training to progressively and constantly talk to about people to change their mindset why we need to change, the reason, and what happens if you do not change and if you want to change what we should do. The CEO mentioned that nobody would be displaced."

(Interviewee 8)

A significant pain point for early adopters of Industry 4.0 was the lack of turnkey solution providers who would coordinate the SME's needs. In the case of SME's who lack technical resources to handle the transformation, this was an area where more support would be welcome.

\section{CONCLUSIONS}

The paper examines Singapore-based SME's readiness to manufacture to implement Industry 4.0 and provides initial insights. We have identified five fundamental driving forces and three main barriers based on interactions with experts. SMEs must adopt a clear strategy and define a roadmap to align their organisation and entire workforce with this Industry 4.0 adoption process's objectives. SMEs will also need to closely network with universities and educational providers to ensure that more significant industry interaction with participation like internships provided to students creates lifelong linkages with the emerging workforce. Industry 4.0 is already challenging the nature of management and leadership competencies, and the empowerment of the younger generation will be a critical factor in the times ahead. On the other hand, while transformation must be top-down, the internalization and real improvements are the people. The employees must buy-in into the SME's transformation process with clear support and guidance from top management to see this initiative succeed.

SMEs are increasingly getting convinced of the benefits of digitalisation and automation. The business case for digital transformation is getting stronger with Covid-19, which may well leave a permanent imprint on the push to adopt and transform. Digitalisation, analytics, and automation will be in significant demand, and firms providing a right work environment with a progressive mindset will reap the rewards in the times ahead. Singapore can play a critical role in ASEAN by leading Industry 4.0 initiatives like advanced manufacturing, innovation, and digital activities across the entire value chain. By leveraging trading, financial, and supply chain strengths in this ecosystem and harnessing member countries' strength in ASEAN, Singapore can lead the way ahead. Singapore can also foray into high value-added manufacturing and design by moving upstream rather than focus on mass commodity specifications. Industry 4.0 enables a great degree of customisation, which augurs well for SMEs in Singapore to move into more attractive spaces within the industry.

This study has fueled exciting insights to explore in future research. We intend to build on the expert interviews to carry out in-depth case studies with SMEs. These case studies will then allow us to examine the credibility of the findings and, in turn, also enable us to discover any new inputs that can build our theory. By examining multiple cases, we expect greater rigor, robustness, and reliability to generalize the research findings (Eisenhardt, 1991). Such an approach will also help mitigate possible adverse effects of sample bias on the study's findings (Yin, 2009). 
Theoretically, the expert interviews point to several relevant theoretical concepts regarding the drivers and barriers of Industry 4.0 adoption in local SMEs, which will be further scrutinized during the 2nd phase of the research project. They include technology push (Godin, 2006) and adoption concepts such as Roger's diffusion of innovations theory (1962), the developmental state (Johnsen 1982), the resource-based view of the firm (Wernerfeld, 1984), proactive and reactive mindset concepts (Bateman and Crant, 1993), strategic leadership theory and business ecosystem concepts (Moore, 1996; Williamsen, P. and De Meyer, A., 2020) as well as business model innovation frameworks (Girotra, K. \& Netyessine, S. 2014; Osterwalder et al., 2010; Taran et al., 2019).

\section{Research Questions for Stage 2 of the Research Project}

1. What are the main factors and elements of Industry 4.0 applications in the case companies?

2. How has, is, or will Industry 4.0 changed/changing/change the way the companies are doing business in terms of the nine building blocks of the business canvas (Osterwalder et al., 2010).

3. How new or intense (innovation intensity: incremental vs. breakthrough) are these changes (if any) to the nine boxes (customers, value proposition, channels, customer relationships, essential resources, activities and partners, cost structure, and revenue streams)?

4. How complex and interrelated were/are/will (be) the changes (one, several, or all building blocks)?

5. Finally, we wish to examine the reach (Taran et al., 2019) of the Industry 4.0 induced innovation(s) in terms of "new to whom" (e.g. new to the company, new to the market, new to the industry, new to the world).

\section{REFERENCES}

Bateman, T.S. and Crant, J.M. 1993. The proactive component of organizational behavior: A measure and correlates. Journal of Organizational Behavior 14(2), pp. 103-118. doi: 10.1002/job.4030140202.

Belton, K.B. et al. 2019. Who Will Set the Rules for Smart Factories? Issues in Science \& Technology 35(3), pp. 70-76.

Chen, Y. et al. 2012. Origins of green innovations: the differences between proactive and reactive green innovations. Management Decision 50(3), pp. 368-398. doi: 10.1108/00251741211216197.

Eisenhardt, K.M. 1991. Better Stories and Better Constructs: The Case for Rigor and Comparative Logic. Academy of Management Review 16(3), pp. 620-627. doi: 10.5465/AMR.1991.4279496.

Eisenhardt, K.M. and Graebner, M.E. 2007. Theory Building From Cases: Opportunities And Challenges. Academy of Management Journal 50(1), pp. 25-32.

Fact-sheet-on-Industry-Transformation-Maps---revised-as-of-31-Mar-17.pdf. $\quad$ no date]. Available at: https://www.mti.gov.sg/-/media/MTI/ITM/General/Fact-sheet-on-Industry-Transformation-Maps---revised-as-of-31Mar-17.pdf [Accessed: 26 September 2020].

Fourth Industrial Revolution. 2020. Wikipedia. Available at: https://en.wikipedia.org/ w/index.php?title=Fourth_Industrial_Revolution\&oldid=979076316 [Accessed: 19 September 2020].

Gioia, D.A. et al. 2013. Seeking Qualitative Rigor in Inductive Research: Notes on the Gioia Methodology. Organizational Research Methods 16(1), pp. 15-31. doi: 10.1177/1094428112452151.

Girotra, K. and Netessine, S. 2014. Four Paths to Business Model Innovation. Harvard Business Review (July-August 2014) 1 July. Available at: https://hbr.org/2014/07/four-paths-to-business-model-innovation [Accessed: 29 September 2020].

Godin, B. 2006. The Linear Model of Innovation: The Historical Construction of an Analytical Framework. Science, Technology, \& Human Values 31(6), pp. 639-667. doi: 10.1177/0162243906291865.

Godin, B. [no date]. "Innovation Studies": The Invention of a Specialty (Part II)., p. 48.

Horváth, D., and Szabó, R. Z. (2019). "Driving forces and barriers of Industry 4.0: Do multinational and small and medium-sized companies have equal opportunities?" Technological Forecasting and Social Change 146, 119-132. DOI: 10.1016/j.techfore.2019.05.021. [no date].

Industry 4.0 Gaining Momentum In ASEAN - Asia IoT Business Platform. [no date]. Available at: http://iotbusinessplatform.com/industry-4-0-gaining-momentum-in-asean/ [Accessed: 19 September 2020].

Initiatives. [no date]. Available at: https://sciath.com/initiatives/ [Accessed: 29 September 2020].

Johnson, C. 1982. MITI and the Japanese Miracle: The Growth of Industrial Policy, 1925-1975. Stanford: Stanford University Press. Available at: http://www.sup.org/books/title/?id=2791 [Accessed: 28 September 2020]. 
Julian M. Müller 2019. Assessing the barriers to Industry 4.0 implementation from a workers' perspective. IFAC-PapersOnLine 52(13), pp. 2189-2194. doi: doi.org/10.1016/j.ifacol.2019.11.530.

Kagermann, H.; Wahlster, W. \& Helbig, J. 2013. 'Recommendations for Implementing the Strategic Initiative INDUSTRIE 4.0 -- Securing the Future of German Manufacturing Industry' ,. acatech -- National Academy of Science and Engineering, München .

Kagermann, H., Wahlster, W. and Helbig, J. 2013. Recommendations for implementing the Strategic Initiative Industrie 4.0 - Final Report of the Industrie 4.0 Working Group. Communication Promoters Group of the Industry-Science Research Alliance, acatech, Frankfurt am Main. Available at: https://www.din.de /blob/76902/e8cac883f42bf28536e7e8165993f1fd/recommendations-for-implementing-industry-4-0-data.pdf.

Launch of A*STAR's Model Factory @ ARTC. [no date]. Available at: https://www.a-star.edu.sg/News-and-Events/astar-news/news/publicity-highlights/launch-of-a-star-s-model-factory---artc [Accessed: 26 September 2020].

MacDougall, W. 2014. Industrie 4.0: Smart Manufacturing for the Future. Germany Trade \& Invest.

Maclaurin, W. R. 1949. Invention and Innovation in the Radio Industry, New York. Macmillan.

Marr, B 2016. What Everyone Must Know About Industry 4.0. Available at: https://www.forbes.com/sites/bernardmarr/2016/06/20/what-everyone-must-know-about-industry-4-0/\#66508a40795f [Accessed: 26 September 2020].

McKewen, E. [no date]. What is Smart Manufacturing? (Part 1A). Available at: https://www.cmtc.com/blog/what-issmart-manufacturing-part-1a-of-6 [Accessed: 26 September 2020].

Miles, M. B., \& Huberman, A. M. (1984). Drawing Valid Meaning from Qualitative Data: Toward a Shared Craft. Educational Researcher, 13(5), 20-30. https://doi.org/10.3102/0013189X013005020. [no date].

Moore, J.E. and Business, H. [no date]. The Death Of Competition: Leadership And Strategy In The Age Of Business Ecosystems., p. 29.

Olsen, T.L. and Tomlin, B. 2020. Industry 4.0: Opportunities and Challenges for Operations Management. Manufacturing \& Service Operations Management 22(1), pp. 113-122. doi: 10.1287/msom.2019.0796.

Orzes, G. et al. 2020. Implementing Industry 4.0 in SMEs: A Focus Group Study on Organizational Requirements. n: Matt, D. T. et al. eds. Industry 4.0 for SMEs: Challenges, Opportunities and Requirements. Cham: Springer International Publishing, pp. 251-277. Available at: https://doi.org/10.1007/978-3-030-25425-4_9.

Osterwalder, A., Pigneur, Y., Clark, T. 2010. Business Model Generation: A Handbook For Visionaries, Game Changers, and Challengers. Strategyzer series. Hoboken, NJ. John Wiley \& Sons.

Rogers, E. 2003. Diffusion of Innovations. 5th ed.

Schwab, K. 2016. The Fourth Industrial Revolution: what it means and how to respond. Available at: https://www.weforum.org/agenda/2016/01/the-fourth-industrial-revolution-what-it-means-and-how-to-respond/ [Accessed: 26 September 2020].

Singapore's companies take leap into advanced manufacturing. [no date]. Available at: https://www.edb.gov.sg/en/newsand-events/insights/manufacturing/factory-forward-advanced-manufacturing-takes-root-in-singapore.html [Accessed: 26 September 2020].

Taran, Y., Goduscheit, R.C. and Boer, H. 2019. Business Model Innovation - A Gamble or a Manageable Process? Journal of Business Models 7(5), pp. 90-107.

Teece, D.J. 2010. Technological Innovation and the Theory of the Firm: The Role of Enterprise-Level Knowledge, Complementarities, and (Dynamic) Capabilities, in: Handbook of the Economics of Innovation.

V Koch, S Kuge, R Geissbauer, S Schrauf 2014. Industry 4.0: Opportunities and Challenges of the Industrial Internet. PWC. Available at: https://www.pwc.nl/en/assets/documents/pwc-industrie-4-0.pdf.

van den Ende, J. \& Dolfsma, W. 2005. Technology-push, demand-pull and the shaping of technological paradigms - Patterns in the development of computing technology. Journal of Evolutionary Economics 15, pp. 83-99. doi: doi.org/10.1007/s00191-004-0220-1.

Veile, J.W. et al. 2019. Lessons learned from Industry 4.0 implementation in the German manufacturing industry. Journal of Manufacturing Technology Management ahead-of-print(ahead-of-print). Available at: https://doi.org/10.1108/JMTM-08-2018-0270 [Accessed: 26 September 2020].

Wernerfelt, B. 1984. A resource-based view of the firm. Strategic Management Journal 5(2), pp. 171-180. doi: $10.1002 / \mathrm{smj} .4250050207$.

Williamson, P. \& e Meyer, A 2020. Ecosystem Edge: Sustaining Competitiveness in the Face of Disruption. Stanford Business Books.

Yin, R.K. 2009. Case Study Research: Design and Methods (4th Edition). Sage, Thousand Oaks.

Zezulka, F. et al. 2016. Industry 4.0 - An Introduction in the phenomenon. IFAC-PapersOnLine 49(25), pp. 8-12. doi: https://doi.org/10.1016/j.ifacol.2016.12.002 